UCRL-ID-130756

\title{
Building an Internet-based Workflow System - The Case of Lawrence Livermore National Laboratories' Zephyr Project
}

\author{
Judith Gebauer \\ Heike Schad
}

\author{
Case Study
}

U. C. Berkeley

Fisher Center of Management and Information Technology

Walter A. Haas School of Business MC 1930

Berkeley, CA 94720-1930

April 1998

This is an informal report intended primarily for internal or limited external distribution. The opinions and conclusions stated are those of the author and may or may not be those of the Laboratory.

Work performed under the auspices of the U.S. Department of Energy by the Lawrence Livermore National Laboratory under Contract W-7405-Eng-48. 


\section{DISCLAIMER}

This document was prepared as an account of work sponsored by an agency of the United States Government. Neither the United States Government nor the University of California nor any of their employees, makes any warranty, express or implied, or assumes any legal liability or responsibility for the accuracy, completeness, or usefulness of any information, apparatus, product, or process disclosed, or represents that its use would not infringe privately owned rights. Reference herein to any specific commercial product, process, or service by trade name, trademark, manufacturer, or otherwise, does not necessarily constitute or imply its endorsement, recommendation, or favoring by the United States Government or the University of California. The views and opinions of authors expressed herein do not necessarily state or reflect those of the United States Government or the University of California, and shall not be used for advertising or product endorsement purposes.

This report has been reproduced

directly from the best available copy.

Available to DOE and DOE contractors from the Office of Scientific and Technical Information

P.O. Box 62, Oak Ridge, TN 37831

Prices available from (423) 576-8401

$\Lambda$ vailable to the public from the

National Technical Information Service

U.S. Department of Commerce

5285 Port Royal Rd.,

Springfield, VA 22161 


\title{
Building an Internet-based Workflow System - The Case of Lawrence Livermore National Laboratories' Zephyr Project
}

\author{
Judith Gebauer \\ UC Berkeley \\ Fisher Center for Management and Information Technology \\ Walter A. Haas School of Business MC 1930 \\ Berkeley, CA 94720-1930 \\ USA \\ gebauer@haas.berkeley.edu
}

Heike Schad

University of St. Gallen, Switzerland

heike.schad@iwi.unisg.ch

Berkeley, April 1998

"Yes, the grass could be greener on the other side but getting there is no easy picnic."

\begin{abstract}
Lawrence Livermore National Laboratories' Zephyr System provides a showcase for the ways in which emerging technologies can help streamline procurement processes and improve the coordination between participants in engineering projects by allowing collaboration in ways that have not been possible before. The project also shows the success of a highly pragmatic approach that was initiated by the end user community, and that intentionally covered standard situations, rather than aiming at also automating the exceptions. By helping push purchasing responsibilities down to the end user, thereby greatly reducing the involvement of the purchasing department in operational activities, it was possible to streamline the process significantly resulting in time savings of up to $90 \%$, major cost reductions, and improved quality. Left with less day-to-day purchasing operations, the purchasing department has more time for strategic tasks such as selecting and pre-qualifying new suppliers, negotiating blanket orders, or implementing new procurement systems. The case shows once more that the use of information technologies can result in major benefits when aligned with organizational adjustments.
\end{abstract}

Keywords: Internet; Electronic Commerce; Workflow Software; Purchasing; Lawrence Livermore National Laboratory; Case Studies. 


\section{INTRODUCTION}

In 1949, San Francisco saw the christening of the California Zephyr train that subsequently connected Oakland and Chicago until 1970. The route of the California Zephyr covered 2,525 miles and took an average of $21 / 2$ days to complete - without changing trains. The innovative stainlesssteel streamliner helped shrink the distance and speed up the time to travel between the U.S. West coast and the industrial areas in the North and East.

Likewise, Lawrence Livermore National Laboratories' (LLNL) Zephyr project helps accelerate business processes from concept through delivery and payment of engineering prototypes by connecting LLNL's engineering, procurement, and suppliers. Initiated in 1994, the project is conducted by LLNL's Engineering Directorate in partnership with Procurement, Administrative Information Systems, and Computations. It shows the benefits of moving an inter-organizational process from a traditional paper-based path to a Web- and e-mail based distributed workflow system. A closer look at the system reveals several factors that were critical to its success like accompanying organizational changes.

Our information draws on several onsite interviews with project participants, as well as information available from LLNL's Web site, project reports, and research papers.

\section{LLNL - PROFILE AND BRIEF HISTORY}

Lawrence Livermore National Laboratory (LLNL) is a Research \& Development (R\&D) facility, located in Livermore, California, and operated by the University of California under a contract with the U.S. Department of Energy. The Lab was established in the early 1950 s to perform research on nuclear weapons and magnetic fusion energy. Its tasks additionally include the stewardship of the U.S. nuclear stockpile. Currently, it hosts six major programs:

- Defense and Nuclear Technology

- Laser Programs

- Non-proliferation, Arms Control, International Security

- Energy Programs

- Environmental Programs

- Biology and Biotechnology Research

Each of the specific programs is sharing support from four more general scientific and engineering Directorates:

- Chemistry and Materials Science

- Physics and Space Technology

- Computation

- Engineering

The Engineering Directorate, the focus of this case study, involves about 2,100 technical and administrative employees and is divided into two organizations, mechanical and electronics engineering. Both organizations share support from five activities, which cut across all areas of Engineering: Engineering Research, Computers, Recruiting, Continuing Education, and Safety and the Environment.

Formally, LLNL is part of the U.S. Department of Energy, and it focuses most of its research on defense related issues. The recent political changes that came along with the fall of the Iron Curtain resulted not only in reduced financial budgets for defense issues, but also lead to a situation where research projects need to be justified on a more rigorous basis than before. Formerly extremely secluded institutions now see themselves in competition with research facilities from all over the world, including the once main enemy Russia. With increased openness 
public awareness is raising and further increasing the pressure on research institutions to deliver high-quality results in an efficient way.

LLNL is currently focusing on the construction of the National Ignition Facility (NIF). This \$1.2 billion facility the size of a football stadium will provide an alternative to traditional testing of nuclear weapons banned in 1996. Instead of underground experiments, NIF will use laser technology and computer simulation as research methods, and additionally conduct other basic research, e.g., on medical uses of laser technology. Operations are scheduled to begin in 2003. Construction and manufacturing will account for over $75 \%$ of the project's cost and involve alliances between the public and private sectors, including not only LLNL but also several other national laboratories and high-tech vendors.

\section{THE CHALLENGE: IMPROVING COLLABORATION AND PROCUREMENT FOR ENGINEERING PROTOTYPES}

Most of the work at LLNL is about engineering, i.e., the design and manufacturing of complex systems. Its outcome is usually based on tight collaboration among engineering specialists, not only within LLNL but also with partners of other research institutions, contractors, and suppliers. In some cases it even stretches beyond national and continental borders.

The exchange of information between the participants of an engineering process is often difficult, especially when different steps such as design, procurement, payment, fabrication, testing, and evaluation are conducted in isolation from each other and when information is stored and exchanged on paper. At LLNL complex administrative processes aggravated the problem. The resulting islands of information encountered difficulties when they needed to interact and collaborate efficiently, and the overall process from concept design to system delivery was slow, error-prone, and expensive. Two bottlenecks were considered to be, the major inhibitors to an efficient, high-quality process:

- Exchange of engineering and administrative documents and

- Purchasing of parts for prototyping.

The project team initiated by Cecil Jordan, Superintendent of the Laser Engineering Division, addressed both problems.

\subsection{InHIBITORS OF EfFEctive COLLABORATION}

Complex engineering projects rely heavily on the effective collaboration among specialists from the initiation through all development phases to the delivery of the final design. Interaction, however, is especially important in the beginning when projects are defined and subsequently outlined in further detail, including the definition of the work breakdown structure for the participants.

Many engineering projects start out with a process called solicitation, defining the legal, technical, and environmental requirements necessary to accomplish project goals while developing a proposal leading to contract award. Participants exchange information about terms and conditions, contact iteration, specifications that contain technical information including engineering and blueprints. Collaboration in later stages evolves around the set up and changes in specifications, drawings, Computer-Aided Design (CAD) models, tooling files, computer software, and other critical path items between the members of the project team.

Traditionally, teams meet in person for engineering reviews and exchange information across the table by marking up drawings, project schedules, and specifications. This process has proven successful as long as information is at hand because it allows immediate, interpersonal communication. However, interaction becomes cumbersome, time consuming, and costly as soon as process participants and information are dispersed. Nowadays common scenarios, such 
as the one where a system is designed in one country, manufactured in another, and delivered on a global basis are greatly inhibited when information and communication are primarily paperbased. Effective collaboration calls for the instant availability of documents, project schedules, and other items such as design libraries, tools, and models and testing data to all project members. The involvement of external development and contracting partners complicates the matter in the sense that external partners are usually supposed to access specific parts of the complete project information only.

At LLNL, engineers in need of items to build prototypes for their projects used to create requirement books that itemize deliverables, often illustrated with some hand sketches. Design engineers conceptualized the needs by generating drawings and related documents, e.g., using a CAD-CAM (Computer-Aided Design-Computer-Aided Manufacturing) workstation. The engineering documents were collected in paper form by the Engineering Record Center (ERC), which spent much time doing the archiving and releasing. Further iterations and reviewing processes between the communication partners required repeated printing and mailing of the documents, slowing down the overall process even further. The use of paper based specifications also limited the amount of information that could be exchanged and increased the number of iterations necessary to reach complete understanding between experts in different locations.

Close interaction between engineers throughout all the steps of an engineering cycle is critical to reach high-quality results in an efficient and effective manner. Additionally, it is important that each step produces output which is usable and valuable to the following phase. Tight collaboration between participants of different stages ensures designs that are reliable, accessible, and easy to manufacture as well as to maintain later on.

\subsection{Inhibitors for fast and Efficient Procurement of Prototype ReLATED PARTS}

After project conceptualization, design engineers decide whether to build the parts in-house or to acquire external vendor services, either to build a prototype or to manufacture the "final" system. LLNL's general policy is to outsource as many jobs as possible in order to keep internal overhead and operating costs down.

Besides weak collaboration functionality resulting from paper-based information exchange, the procurement of parts for prototyping was considered the other major inhibitor of an efficient engineering process. LLNL's purchasing department has had Electronic Data Interchange (EDI) systems in place for years, a valuable mechanism for computer-to-computer connections to process transactions in a cost and time efficient way. However, restrictions inherent in the structure of EDI messages as well as the high setup and operations cost call for large volume transactions of standardized, commodity goods to make the overhead feasible and worthwhile.

Most of the parts involved with prototyping fall outside the category of commodity goods, however. They are frequently non-standard and complex to describe and specify. The entire procurement process requires close interaction between the end user engineer and the vendor. While transaction volumes and order frequencies are low, demands are usually unpredictable and often come on short notice. Together, these factors defy the economic set up and use of EDI-systems for the purchasing of prototype related items. Nevertheless, the capability to build prototypes within a short time frame is a major strategic issue in a research environment where success cannot be measured in hard dollar figures.

Engineers expressed concern about the length and the quality of the process, much because:

- Procurement was involved in most of the purchasing acts, and again

- Communication between engineering, procurement, and the vendors was mostly paperbased. 


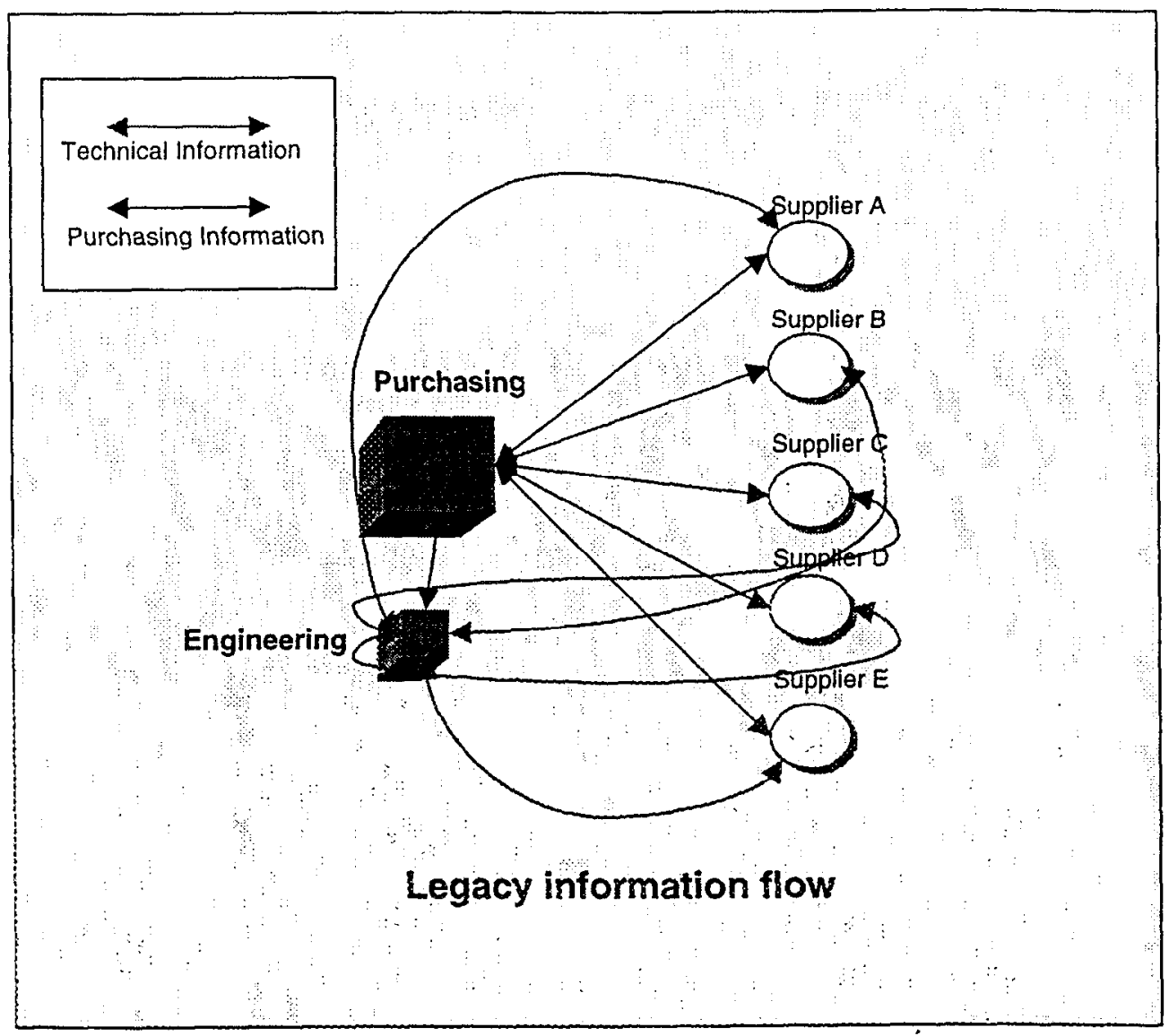

Figure 1: Information Flow Prior to Zephyr

Prototype modules usually consist of many single items, most of which required the processing of separate purchase order forms. With the procurement department being involved in purchasing of most of the items, the administrative overhead frequently exceeded the actual value of the items. The additional "non-expert" layer of communication between the end user engineer and the vendor caused another problem (Figure 1). Concerns about unclear requirement definitions on the vendor side as well as about marginal quality and schedule impacts on LLNL's side were the frequent result of this structure.

Similarly, the procurement process was hindered in terms of cost, time, and quality by the fact that the communication of engineering information within LLNL as well as between the Lab and external vendors was mostly based on paper. In line with regulatory requirements, LLNL often purchases items via a bid procedure, involving the following steps:

- Hand over request to the purchasing department for approval

- Set up Request for Quote (RFQ)

- Mail RFQ to prospective suppliers to solicit bids

- Select best bid

- Notify winning bid as well as the other bidders

- Send out comprehensive information and complete specification to the selected supplier

- Receive shipment and initiate payment

Table 1 summarizes the steps, showing the most common means of communication with each step as well as their "administrative" owners. 
Table 1 - Purchasing Prototype-Related Items Prior to Zephyr

\begin{tabular}{lll}
\hline \multicolumn{1}{c}{ Process Steps } & $\begin{array}{l}\text { Communi- } \\
\text { cation via }\end{array}$ & Owner \\
\hline 1 Concept & Paper & Engineering \\
2 Collaborative design & Paper & Engineering \\
3 Approval & Paper & Purchasing \\
4 Solicitation & Paper & Purchasing \\
5 Supplier selection & Paper & Purchasing \\
6 Award & Paper & Purchasing \\
7 Technical data transfer & Paper & Engineering \\
8 Shipment & Paper & Purchasing \\
9 Delivery & Paper & Purchasing \\
10 Receipt & Paper & Purchasing \\
11 Invoicing & Paper & Purchasing \\
12 Payment & Paper & Purchasing \\
\hline
\end{tabular}

As a result of the administrative complexities and paper-based communication, the procurement of prototype-related items typically took several weeks, in some cases even months. The average period for the purchasing of printed circuit boards, for example, was 20-25 days. In the case of an assembly fixture the process took 56 days with the steps from design release to contract award already accounting for 10-29 days. Note that these figures do not include the time that LLNL usually took to initiate payment.

\section{THE NEW CONCEPT - OUTLINE OF THE ZEPHYR SYSTEM}

With Zephyr, the Internet- and Web-technology based system for the procurement of prototyperelated items, LLNL pursued two main objectives:

- Improve the quality of the engineering process through better collaboration between engineers in design and manufacturing

- Reduce time and cost of procurement

To achieve these goals, the project team decided to move as many paper-based steps as possible, including payment, to electronic media. Today, Engineering's CAD systems are integrated with business systems that link procurement and finance, commercial vendors, and end users.

The project was initiated in an unusual way -- unofficially and behind the scenes, by the engineering and computer departments, not by Procurement. In the beginning there was no official funding and the system was developed by a couple of enthusiasts after dark. They initially attempted to introduce a common format and central location for the storage of engineering documents. The system promised easy transfer of documents between different CAD systems and thus improved collaboration between engineers. In a second step the team also considered business systems, as it became clear that the connection between procurement and designers was essential. By the time the prototype was ready and the benefits became more obvious the concept gradually gained acceptance from top management and eventually achieved four years of funding through the Department of Energy. 
The Zephyr system as it stands today is among others based on Internet technology to support communication around the creation of engineering data, procurement of prototype parts, and for fabrication. The issues of communication and cooperation tackled by the project are common for large-scale R\&D facilities. They are also becoming more and more important in business environments as organization-spanning cooperation increases. The following sections provide a more detailed look at the system.

\subsection{DESCRIPTION}

Zephyr is a Web- and email-based system supporting the paperless, distributed workflow for the procurement of non-commodity items. It is the outcome of the initial idea to improve collaboration among engineers by making engineering documents centrally accessible. The system was first based on proprietary software that was developed by Lawrence Berkeley Laboratories. Internetbased technologies, however, proved to be very handy to establish a common communication infrastructure and their availability gave the project a major push. In short, the system stores complex data in a central database and directs the workflow around them via Web forms and email.

Since March 1995, Zephyr has been piloted for the purchase of printed circuit boards. It is, however, scheduled for major extensions over the next years. The system links engineering and procurement throughout all major process steps and connects Laboratory employees with each other and with suppliers and partners across the nation and internationally. External partners are currently mostly small and medium sized enterprises (SME's).

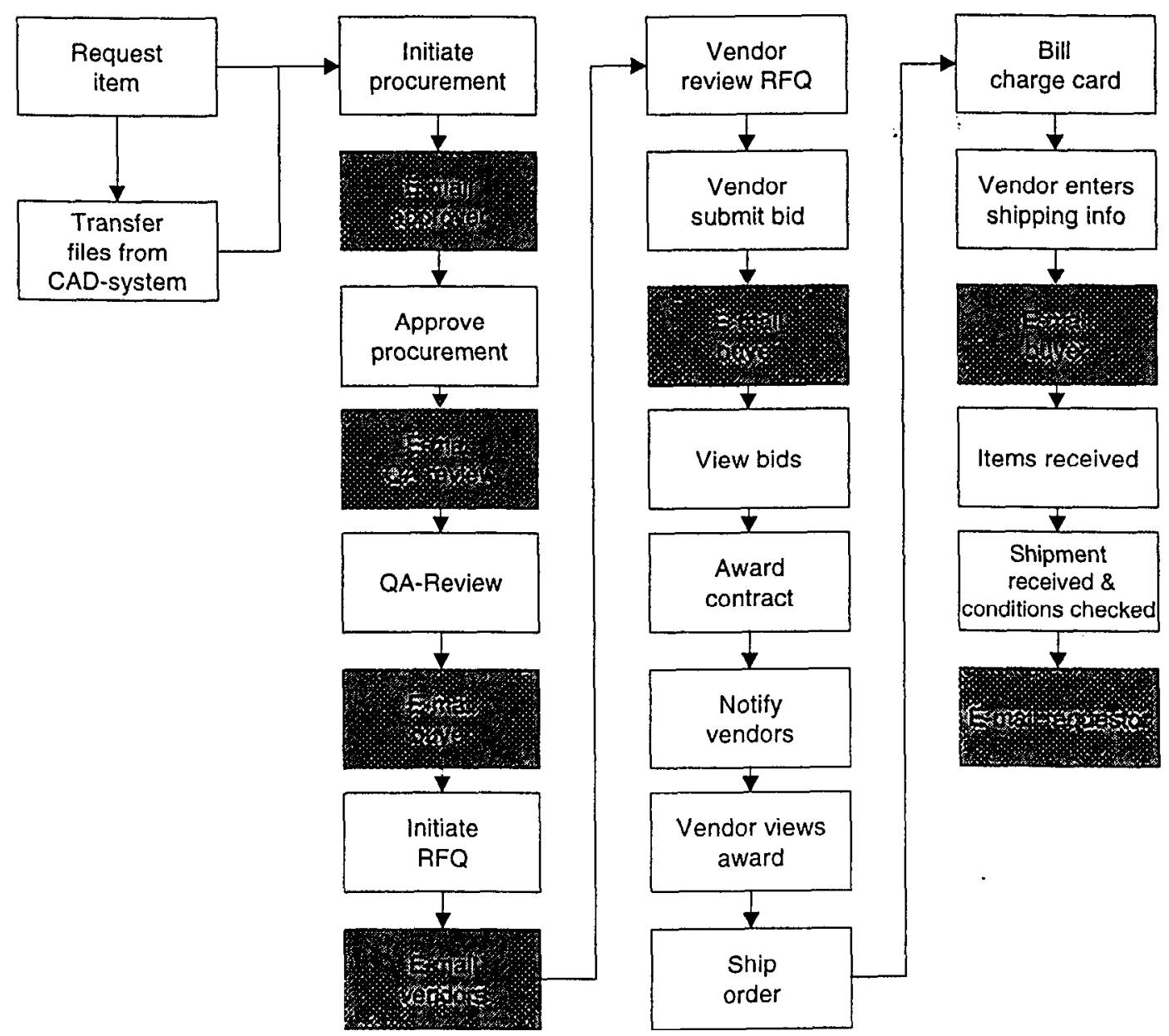

Figure 2: Zephyr's E-mail Driven Workflow Process 
The workflow process supported by Zephyr starts out after an engineering design package is approved for release followed by the decision that a prototype should be built. It is initiated upon a user request to purchase engineering items (Figure 2); in case of printed circuit boards, a couple of requests are issued per day.

To issue a requisition, fabrication data files describing the required design are transformed into a commonly downloadable format and then transferred into the Zephyr database via the Engineering Document Transaction System (EDTS). The files can later be accessed, using a Web browser, downloaded, and printed. The system automatically assigns a job number for future reference and, depending on the size and other details of the job, e-mail is sent to the approval manager (within Engineering). While requisitions are not necessarily very detailed, they do contain a brief description of the required item and the desired delivery terms.

Subsequently, a 'quote sheet' is generated from the fabrication data. This electronic form can be seen as a master document that following activities refer to and that is eventually sent out to the vendors. While it defines the job and contains enough information to allow vendors to bid on the offer, it does not enable them to actually build the prototype.

For procurement of items over $\$ 5,000$ the procurement department has to provide its approval. While the designated procurement quality approver is notified via e-mail, the actual file containing the details of the request remains on the server. After accessing the file via a Web browser, the approval manager reviews it, adds her approval/disapproval to the record, and resubmits the form. For items under $\$ 5,000$ no approval from Procurement is needed, i.e., Engineering directly initiates the bidding process (Figure 3). The latter is the case for about $70 \%$ of the volume of custom manufactured items in Electronics Engineering.

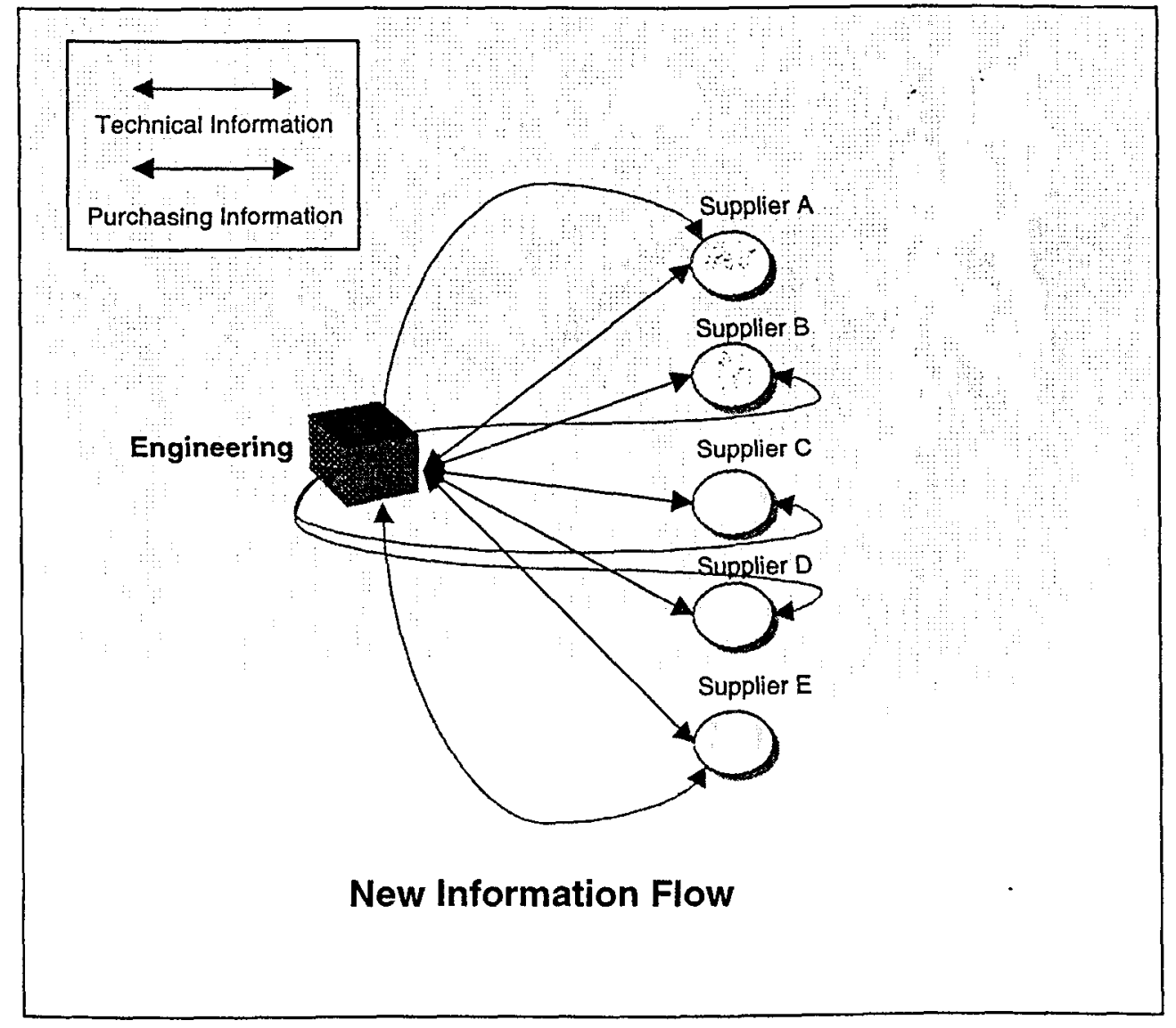

Figure 3: Information Flow after Implementing Zephyr 
In the next step, a Request for Quote (RFQ) is generated and a group of selected vendors, typically 3 or 4 , are notified of it via e-mail.

At this point it should be mentioned that, in line with the LLNL's internal requirements, all vendors of LLNL are pre-qualified. In order to participate in the Zephyr system suppliers need Internet and Web access and must be able to accept payments via corporate credit card (ProCard), which in LLNL's case is secured by the First National Bank of Chicago. While ProCard is LLNL's primary payment mechanism, the Zephyr system is generic enough to be easily adapted to other mechanisms such as existing purchase and blanket orders.

LLNL pre-qualifies all its vendors using surveys to assess product quality and manufacturing capabilities. Vendors are ranked and categorized into groups of competencies according to their capabilities. The Lab subsequently keeps track of their performance using a performance database. Currently about 30 vendors have been pre-qualified for participation in the Zephyr system, 12 of which are actively using it. LLNL has been cutting down the number of its suppliers during the past years. The current number of 3,000 vendors dropped from 6,000 a couple of years ago. Plans for the future indicate about 1,000 vendors.

The RFQ is handled by a Technical Release Representative (TRR), who selects the vendors, sets the deadlines for bids, and notifies the vendors via e-mail. Since not all - especially small vendors are connected to e-mail all the time, he often uses the telephone additionally to ensure everybody knows about the invitation to bid. Informed by the 'trigger e-mail,' vendors access LLNL's web site where they find the specifications necessary to bid.

Security turned out to be a very important issue. Zephyr provides secure electronic forms for all process steps, e.g., for vendors to submit their bids. Bidders can only see the public quote sheet and their own bids, but not the bids from their competitors, and not even quote sheets for offers that do not apply to them. Only authorized staff inside LLNL can place quote sheets, or follow up on the shipping or receiving status. The setting up of secure areas inside the Netscape browser system was very important for the success of the project and required significant time and effort.

After reviewing the RFQ, vendors submit their bids. They do so by filling out the form they find on LLNL's Web site and uploading their bids. Again, notification about completed activities is communicated via e-mail. Sometimes the entire process takes no longer than 4 hours.

After the deadline, a representative at LLNL reviews the incoming bids, chooses the winning bid, and awards the contract. Again participants, i.e., successful as well as unsuccessful vendors, are notified via e-mail.

The successful vendor is given access to additional engineering data necessary to build the required parts. A ProCard number is assigned to the process which will be used subsequently as a reference number for payment. After completing the job the vendor notifies LLNL via e-mail that the item is now ready for shipping.

The shipment notice instantly triggers the payment process. Via the ProCard mechanism, payment gets credited to the vendor's bank in most cases within 48 hours and mostly using electronic funds transfer.

The vendor is asked as a courtesy to log back on to LLNL's Web site to transmit the shipping number and other tracking information. By capturing this information LLNL is able to monitor the shipment via the Internet. 
The process is concluded upon receiving the shipment. After checking the condition of the items at the receiving dock, the end user is informed via e-mail that she can pick up her order. The loop of the triggered procurement process is closed.

To summarize, communication around the procurement for engineering prototypes is now entirely supported by the electronic Zephyr system (Table 2). The end user community (Engineering) is responsible for the whole process and Procurement only becomes involved in cases of exceptions, such as for the approval of purchases over $\$ 5,000$, to define the process infrastructure, e.g., by setting up supplier contracts, or to monitor supplier performance.

Table 2 - Purchasing Prototype-Related Items Using Zephyr

\begin{tabular}{lll}
\hline \multicolumn{1}{c}{ Process steps } & Medium & owner \\
\hline 1 Concept & CAD-system & Engineering \\
2 Collaborative design & Web & Engineering \\
3 Approval & E-mail & Engineering \\
4 Solicitation & Web/ E-mail & Engineering \\
5 Supplier selection & E-mail & Engineering \\
6 Award & E-mail & Engineering \\
7 Technical data transfer & Web/ E-mail & Engineering \\
8 Shipment & Web/ E-mail & Engineering \\
9 Delivery & Web/ E-mail & Engineering \\
10 Receipt & E-mail & Engineering \\
11 Invoicing & ProCard & Engineering \\
12 Payment & ProCard & Engineering \\
\hline
\end{tabular}

\subsection{PILOT ROLL-OUT OF ZEPHYR}

The initial rollout of Zephyr amounted to $\$ 200,000$. Resolving security issues and creating customizable restricted access areas, however, required significant additional effort over a period of about 12 months. About forty employees use the current pilot. Its success is based on several factors.

\section{- Procurement of Commodities versus Non-Standard Prototype Items}

While for the procurement of commodities and high-volume off-the-shelf items EDI solutions have been in place at LLNL for a long time, fabricated items for prototypes used to be ordered in traditional ways using paper documents and communication via telephone and fax. Low volumes, highly unpredictable demand, and the complexity of the items prevented the economic use of large-scale automated systems. However, the timely delivery of high-quality prototypes is a critical issue for the Laboratory.

The Internet and World Wide Web provided the basics to develop a system for the fast communication of complex engineering data and allowed for additional administrative changes that streamlined the entire process.

Printed circuit boards provided a good start to test the system because an industry-wide standard (International Graphics Exchange Standard) exists that helps communicate complex technical specifications in a clear way. Also, the project team assumed that vendors in this high- 
technology area would be versed enough with innovative technologies to reach adequate acceptance and participation.

\section{- Designed to Handle Standard Situations}

In order to keep development efforts within tight budget limits, the system is designed to mainly handle standard situations, meaning vendors deliver good quality in time. Exceptions have to be handled manually. As a result, the overhead costs could be kept reasonably low.

Close and long-established relationships with vendors are a prerequisite for the arrangement to initiate payment upon shipment notice, clearly not an option for relationships that are created "on the fly."

\section{- Signing Up Vendors and Selecting Pilot Partners}

A main success factor for Zephyr was to sign-up an acceptable number of suppliers. To avoid the time-intensive process of setting up new relationships, the project team targeted only vendors LLNL was already doing business with. In line with the Lab's general policies these vendors were pre-qualified, i.e., met LLNL's standards in terms of product quality and reliability.

The project team asked the end user engineers within the optics and mechanical fabrication departments to name their favorite vendors and then approached these vendors to find out about their general interest to participate in the system.

It turned out that small to medium sized companies with up to several hundred employees were much easier to win than larger ones; they showed more flexibility in deciding about the changes that the participation in Zephyr would require. Several features of the system helped to keep the risk for the participants relatively low and made it altogether easy for the Zephyr team to sign up a reasonable number of participating vendors.

In order to participate in the system a vendor basically needs to establish access to the World Wide Web and e-mail and corporate credit card capabilities. Both can be obtained at relatively low cost: Internet-connections usually amount to less than several hundred dollars and are followed by access costs which can be as low as approximately $\$ 25$ per month. Obtaining credit card capability costs about $\$ 500$. In exchange, LLNL offers their vendors extremely fast payment as compared to the traditional weeks, and a sound basis for regular future business. Additionally, vendors are given the opportunity to access technical specifications in electronic form which greatly facilitates their handling, and reduces the possibility of errors.

Overall, about 30 suppliers have been signed up for participation in the system, most of which are small and medium enterprises. Twelve vendors are currently actively involved in Zephyr's pilot for the procurement of printed circuit boards.

\section{- Up-Front Negotiations}

After the general sign up of system participants, agreements on more detailed levels had to be made. Those regard issues such as the use of the system or the file format of the data that is being transferred between LLNL and its vendors. Suppliers need to know the file format they have to download from the web; they have to check the transformation in their own internal systems, and they have to learn about the correct way of accessing and filling out the online forms.

While these aspects are not necessarily a very complex issue, altogether, they are important to be considered in order to avoid subsequent problems, especially in cases where suppliers have little or no online experience.

\section{- Simple System Architecture}

The Zephyr system uses a relatively simple architecture that makes it easy to handle and limits access costs. This also makes it generic and flexible enough to be easily applied to different 
settings and processes. While all complex engineering data reside on the LLNL's internal system, workflow processes are routed and steered via Web-based forms, supported by trigger emails.

Based on an open architecture, the system establishes a generic communication infrastructure system that supports the flow of information from the engineers' design boards to manufacturing, to procurement, and eventually onto the suppliers' screens, and that couples computer-aided design tools with electronic commerce applications. Thus, it supports the exchange of complex technical specifications and drawings between heterogeneous environments helping to improve collaboration between different engineering groups, as well as administrative tasks like internal approvals, bidding, and ultimately payment.

\section{- Customized System Setup}

The current setup of the Zephyr pilot is very much tailored to the needs of the Technical Release Representative (TRR) who plays a central role in the procurement of printed circuit boards. After receiving the requests from the end users (engineers), he performs several formal checks and then generates the quote sheet. This means, he initiates the procurement process, determines the complexity of the job, sets up the RFQ, chooses and contacts potential vendors, and finally makes the selection and awards the contract.

Among other factors, it was the setup of Zephyr that allowed LLNL to have the procurement of printed circuit boards administered by just one person instead of the 18 people that were involved in this job before. The flexibility of the system's infrastructure makes the customized approach easy which ensures acceptance among end users and helps to apply the system to a variety of different settings.

\section{- Security Aspects}

Security aspects were very important for the acceptance of the system. While the project team was less worried about general break-ins, it was considered essential to ensure a variety of secure areas, granting different users access rights and data views according to their individual roles. For example, vendors should always only see their own bids, but not the bids of their competitors. The task was solved in part by using Netscape's Commerce Server and RSA secured forms, but also required significant development efforts by LLNL's computer directorate itself. The team found it especially difficult to create a secluded Web server that would allow individualized access to the stored data, but would not allow external users to perform other functions such as anonymous login, $\mathrm{ftp}$, or X-Windows. The tasks of making the initial Zephyr pilot simpler and compliant with LLNL's security requirements account for the biggest part of the project cost as of today.

To determine the adequate level of security for different areas of the system in terms of feasibility and bottom-line value, LLNL performed cost-risk analyses. Time dependency of the data was eventually chosen to be the major indicator of security requirements - the longer a piece of information stays valid, the more strongly it needs to be protected. To test the system, LLNL used internal computer experts who were allowed to perform all possible break-in attempts.

\section{- Administrative Changes}

The full benefits of the new system (see Section 5) result as much from the implementation of the Zephyr pilot, i.e., the use of information technology, as from administrative changes of the underlying procurement process.

In the new setting, the end user of the requested parts are empowered to do most of the transactions within their own domain without having to use purchase orders and to go through Procurement. The latter is now in the position where it can concentrate more on strategic issues, such as establishing and managing vendor relationships. 
Although the benefits are obvious today, the project which was set up by Engineering and Computational Services initially encountered concern from Procurement, which was about to be circumvented by the new system. Eventually, re-organization in central Procurement helped jumpstart the project. The new procurement group shared the vision with Engineering about the benefits of streamlining the process and relying on outsourcing as much as possible. It was also well aware of the difference between procurement of commodities and non-standard items as it applies to engineering products. A presentation of the Zephyr concept as best practice at the DoE Headquarters eventually lead to a major progress of the project in terms of support and funding.

\section{BENEFITS}

The single fact that a job which was previously done by 18 people is now handled by one person makes it obvious that the new system brings enormous benefits in terms of process streamlining. Not all of the benefits can be quantified, though.

\section{- Time savings}

One of the major project goals was to reduce process lead-time. This objective was achieved to an impressive extent, with time savings ranging from $60 \%$ to $90 \%$.

- The procurement of printed circuit boards, which traditionally took 20-25 days, can now take less than 2 days.

- In a series of pilot procurements of non-standard optical components, the bid package, RFQ, and award process cycle took less than 5 days using the combined Zephyr and ProCard process compared to much longer cycle times associated with paper-based processes.

- In the case of an assembly fixture the procurement cycle time dropped from the typical 56 days to 5.5 days.

The time savings do not only result from the substitution of paper-based communication by the electronic Zephyr system, but to a large extent also from administrative changes. Regarding printed circuit boards, those changes alone reduced the purchasing process from weeks to days. The use of Zephyr then further squeezed lead-times into what is sometimes just a matter of hours. Additionally, LLNL receives the incoming bids now in a standardized format. This reduces potential errors and makes bids easier to compare, which again speeds up the decision process from the Laboratory's side.

Fast delivery of research results and prototypes is essential in an environment where results are often not measured in hard dollar figures. It enables the Lab to acquire funding for additional projects and helps to improve the overall research quality.

\section{- Cost Savings and Improved Product Quality}

As important as the time reductions, significant cost savings also occurred. In some cases these are directly linked, e.g., when a system allows reducing the level of staff necessary to perform a given task. In the case of Zephyr, administrative and IT related changes together allowed the reassignment of 17 people involved in the procurement process of printed circuit boards, a task now accomplished by just one person.

Initially, the internal financial department raised some objections because payment upon receipt was preferred rather than on announced shipment. The system development team, however, could explain convincingly that the Lab has been maintaining relationships with the selected vendors over a long period of time, and that the vendors were very aware of the fact that if they did not meet the expectations they risked losing future business. 
The fact that payment is now initiated much faster than in the past actually allowed LLNL's procurement officer to renegotiate contract conditions, resulting in "same as cash" discounts worth $\$ 120,000$ in just two months.

In the past, some vendors, especially smaller ones, were not able to do business with the LLNL. at all because of its slow payment cycle that could easily take more than 180 days. With the new system LLNL can in principle choose from a larger number of vendors. This increases competition and opens new opportunities for cost savings and improved product quality.

Additional cost (as well as time) savings are gained from the improved communication between the end user engineer and the suppliers. Misunderstandings and the cost related with it are now avoided because the "experts" communicate directly with each other and the former additional administrative information filter is circumvented. Moreover, IT-based communication is often more precise and the data transmitted is more detailed than in the case of paper and fax. Also, by the use of forms, the Lab as well as the vendors are forced to submit all the information necessary to complete the job.

As an outcome of the standardized bidding process, bids are now easier to handle and to compare. With the same effort, LLNL could now obtain more bids for one offer. Cost savings might then result from the increased competition and the wider range of the bids. This variety is supported by the usage of the Web, because it is now relatively easy for prospective vendors to submit bids, independently from their geographic location. LLNL has not made use of this feature yet, however.

\section{- Improved Communication and Collaboration}

The elimination of paper based communication between LLNL's engineers and the suppliers and the central storage of documents that are now accessible to everybody involved in a design, also helped improve collaboration and ultimately enabled higher-quality results as well as significantly accelerated decisions. Truly concurrent engineering is greatly facilitated, involving engineers and other experts within the Lab as well as external partners. This includes suppliers who now have the potential to play a much more active role in the projects. Eventually, the design products will more closely comply with LLNL's general request of designing prototypes that are efficient to manufacture and easy to maintain.

\section{SUMMARY AND OUTLOOK}

Zephyr is an integrated computer system that enables the seamless flow of information from the engineers' design boards to manufacturing, procurement and eventually onto the suppliers' screens. By coupling computer-aided design and manufacturing tools with electronic commerce applications, the system allows the exchange of complex technical specifications and drawings, supporting collaboration between different engineering groups, as well as the processing of administrative tasks, e.g., internal approvals, bidding, and payment. While complex data stays on an internal LLNL database server, workflow processes around them are routed and steered through Web based forms and electronic mail. The system enables rapid agreement on design changes among geographically dispersed project participants. It speeds up internal approval as well as procurement processes through external links with parts suppliers.

The case shows very convincingly how organizational redesign and the use of information technology together lead to significant benefits. From the start, the project team saw IT as a means to overcome inefficient organizational structures and procedures. Ultimately, it was the combination of streamlining responsibilities and procedures in the procurement process with using the Internet and e-mail that made LLNL more efficient and competitive. 
The fact that the Zephyr system is largely based on open standards technology, as well as its general architecture, make it a very generic concept, which is easily adaptable to other settings, inside and outside of procurement and engineering tasks.

The case also shows a very pragmatic approach - procurement via Zephyr is not a fully automated process: it does in fact require significant human intervention. Although there are plans to take some further steps in that direction, e.g., automating the supplier selection process, the system deliberately does not cover all possible situations. Rather, it is designed to handle standard situations. Although exceptions, such as the situation when vendors fail to fulfill orders in a correct or timely manner, have to be detected and taken care of "manually," the fact that the whole set up is based on long-term and ongoing relationships prevents these situations from getting out of hand. As a result, the costs and efforts to develop the system could be kept reasonably low; the outcome is a highly flexible concept that has been rewarded with high acceptance from users inside and outside the Lab, and has gained great attention from top management.

Currently, Zephyr is implemented as a prototype for the procurement of printed circuit boards, demonstrating the concept's feasibility. Although covering only a small part of Engineering, the system shows significant benefits in terms of improved collaboration, shorter engineering cycles, reduced procurement time, and lower overall costs. In late 1997, LLNL's top management awarded the project team "for developing a revolutionary new approach to engineering procurement with shows promise for emulation at the Laboratory and beyond." The recognition is a thrilling experience and late satisfaction for Cecil and his team, who set out to develop their vision in secret and after hours.

As a result of its initial successes, the system will soon see major extensions in terms of functionality, scope, and reach. Recently, LLNL has been approached by a large Mid Western bank concerning its interest in licensing the Zephyr system. At LLNL itself, the 1998's plans for Zephyr continue to focus on collaboration, both national and international, aiming at expediting technology development. Starting in June 1998, Zephyr will become fully integrated into LLNL's institutional business system. Any authorized vendor will then be able to access to the system Labwide. This decision was driven by the concern to expedite engineering procurement related to the National Ignition Facility (NIF) (Section 2). The project team thus faces the challenge of not only having to enlarge the system to handle transactions in excess of $\$ 200$ million, but also to show its viability in a large-scale "real life" setting.

\section{REFERENCES}

Tom Field: Great Expectations, in ClO, September 15, 1997, pp. 123-132.

How Bank of America is piloting electronic payments via the Internet, in I/S Analyzer Case Studies, Vol. 34, No. 12, December 1995, pp. 11-15.

Cecil W. Jordan et al.: Zephyr: "Streamlining Deliverable From Concept Through Payment", UCRL-JC-128507, Lawrence Livermore National Laboratories, Livermore, Calif. Prepared for the National Association of Purchasing Management, Phoenix, Arizona, November 11, 1997.

Cecil W. Jordan et al.: Using the World-Wide Web as a Medium for Concurrent Engineering and Rapid Prototyping, Engineering Thrust Area Report, UCRL-ID-122242-95, Lawrence Livermore National Laboratories, Livermore, Calif. Presented at $40^{\text {th }}$ Annual Department of Energy Contractors Purchasing Managers' Conference, Albuquerque, New Mexico, October 1996.

Cecil W. Jordan et al.: Zephyr: A Secure Internet-Based Process to Streamline Engineering Procurements Using the World Wide Web, Engineering Thrust Area Report, UCRL-ID-53868-96, Lawrence Livermore National Laboratories, Livermore, Calif. Presented at CALS International Exposition, Long Beach, Calif., October 1996. 
Arie Segev, Jaana Porra, and Malu Roldan: A Bigger Picture of Internet Security: The Case of Bank of America, Fisher Center for Management and Information Technology, UC Berkeley, Working paper 97-WP-1020, Berkeley 1997.

Zephyr Homepage: http://zephyr.Inl.gov.

Lawrence Livermore Laboratories Homepage: http://www.llnl.gov.

To collect data for this case study, we had the opportunity to conduct several interviews onsite with a number of people from two of LLNL's central Directorates, Electronics Engineering and Computation. Together they are responsible for the initiation, implementation, and, currently, the use of the system:

- Rudy Cavitt, Leader of the Laser Programs Design and Drafting Group (part of the Laser Engineering Division)

- Ray Gonfiotti, providing field support for the Electronic Manufacturing Group

- Cecil W. Jordan, Superintendent of the Laser Engineering Division

- Kenneth V. Luu, Leader of the Electronic Manufacturing Group (part of the Electronics Engineering Technologies Division)

- Fred E. Warren, Project Leader in the Computation Directorate

The interviews were conducted by Peter Buxmann and Judith Gebauer, Sept 16, 1997, and Oct 3,1997 . We want to thank all participants for their kindness, time, and expertise. 


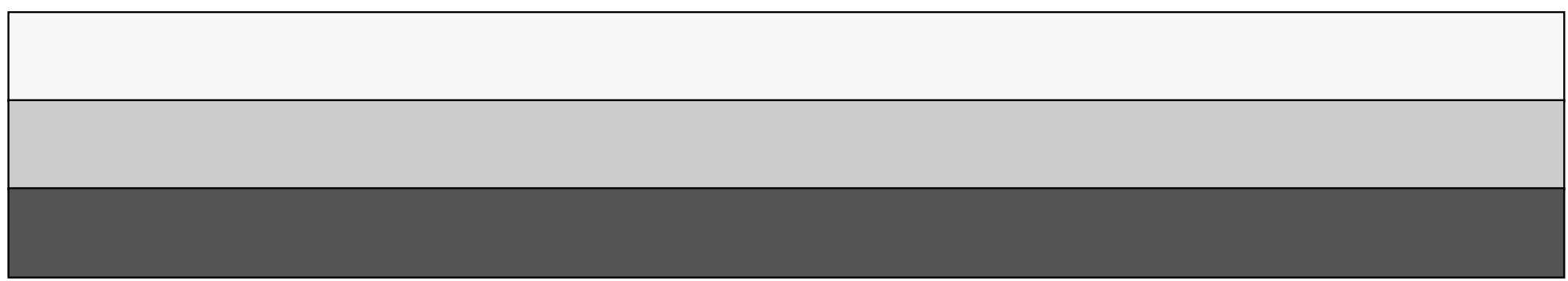

